Proceedings of SALT 30: 450-463, 2020

\title{
Positively polar plurals: Theory and predictions*
}

\author{
Dorothy Ahn \\ Rutgers University
}

\author{
Ankana Saha \\ Harvard University
}

Uli Sauerland
ZAS

\begin{abstract}
Several researchers have suggested that languages vary as to whether number marking on noun phrases is obligatory or optional (Arka \& Dalrymple 2017; Biswas 2013; Bylinina \& Podobryaev 2020; Corbett 2000; Kim 2005). We develop an implementation of this idea within a theory that assumes that the plural is a semantically vacuous, unmarked number (Sauerland, Anderssen \& Yatsushiro 2005 and others). We then explore the semantic consequences of this proposal. One striking prediction of the proposal is that plural nouns should be ungrammatical in antitone environments in languages where number marking is optional, i.e. plurals should be positive polarity items in optional number languages. This prediction arises because the plural form is equivalent to the number neutral bare form in optional number languages. The Efficiency requirement of Meyer (2013) therefore predicts that plurals require local exhaustification in optional number languages since otherwise the bare form is more efficient. Because bare forms are impossible in obligatory number languages, plurals are not predicted to be positive polarity items in such languages. We conclude with an outlook on how to empirically verify the predictions of the theory we presented.
\end{abstract}

Keywords: number, exhaustification, presupposition, Bangla, Korean

\section{Proposal}

The idea that languages differ as to whether number marking on nouns is obligatory or optional is suggested in a number of places (Arka \& Dalrymple 2017; Biswas 2013; Bylinina \& Podobryaev 2020; Corbett 2000; Kim 2005). Most directly in support of optionality is data from languages with a general number in opposition to singular, plural and possibly other numbers (Corbett 2000). For example, Corbett \& Hayward (1987) report that Bayso exhibits a contrast between the nominal forms lúban (lion-GENERAL, 'one or more lion'), lubán-titi (lion-SG, 'exactly one lion'),

* We thank Gennaro Chierchia, Utpal Lahiri, and the audience at SALT 30 for their helpful comments and suggestions. This project is supported by grant DFG SA 925/11-2. 
luban-jaa (lion-PAUCAL, 'a few lions'), and luban-jool (lion-PL, 'a lot of lions'). Bayso general number, we propose, should be analyzed as the absence of number marking.

Number optionality has also been claimed for languages such as Bangla (Biswas 2013), Buriat (Bylinina \& Podobryaev 2020) and Korean (Kim 2005), where the singular ending is null unlike in Bayso. The evidence that bare nouns in languages such as Bangla and Korean can be unspecified for number in addition to being singular is shown in (1). In (1b) for Bangla and (1c) for Korean, the indefinite bare nouns do not lead to a singular inference.

(1) a. Kim ate an apple for lunch. $\rightsquigarrow$ Kim didn't eat two apples for lunch.

b. Rita lunch-e aapel kheyeche.

Rita lunch-LOC apple eat.PRES.PERF.3

'Rita ate $\{$ an apple / apples $\}$ for lunch.'

[Bangla]

c. Jin-un sakwa-lul mek-ess-ta.

Jin-TOP apple-ACC eat-PAST-DECL

'Jin ate $\{$ an apple / apples $\}$ for lunch.'

[Korean]

In this paper, we explore the idea that number may be obligatory or optional in a current theoretical perspective on the semantics of number marking. Specifically, we assume that an obligatory number language requires nouns to occur in the form NOUN+SG or NOUN+PL, while an optional number language allows a choice between three forms: the bare noun stem NOUN in addition to the two number marked forms that the obligatory number languages allow. We also present some preliminary empirical support from Bangla and Korean.

Five theoretical assumptions we adopt are listed in the following:

i. Nominal stems and plural number are unmarked for number (Hoeksema 1983; Sauerland 2003; Sauerland et al. 2005; van Eijck 1983)

ii. Number marking is interpreted in the noun phrase (Mayr 2015)

iii. A propositional constituent must not be equivalent to any proper subconstituent of it (Meyer 2013, 2014, 2015; Sauerland 2018)

iv. Exhaustification must not lead to global weakening (Chierchia, Fox \& Spector 2012; Fox \& Spector 2018)

v. Exhaustification can apply to any propositional node subject to the previous two restrictions (Chierchia 2013 and others)

Let us briefly review the assumptions i, ii and v. Assumptions iii and iv concern primarily the distribution of exhaustification operators, and will be introduced in 
Ahn, Saha, and Sauerland

Section 2. Following Sauerland (2003), we assume that bare nominal predicates are numberless as illustrated in (2a) for horse. ${ }^{1}$ We furthermore assume that the singular and plural morphemes SG and PL are predicates with the interpretations in (2b) and (2c).

$$
\begin{array}{ll}
\text { a. } & \llbracket \text { horse } \rrbracket=\lambda X . \text { atomic }(X) \wedge \forall x \sqsubseteq X(\text { atom }(x) \rightarrow x \text { is a horse }) \\
\text { b. } & \llbracket \mathrm{SG} \rrbracket=\lambda x . \text { atom }(x) \\
\text { c. } & \llbracket \mathrm{PL} \rrbracket=\lambda x .1
\end{array}
$$

Following Mayr (2015), we assume that SG and PL are interpreted as a sister to the noun. Slightly deviating from Mayr's proposal, we assume that number combines conjunctively with the nominal predicate. But we follow him again in assuming that an exhaustification operator applies to number internal to the noun phrase. For concreteness, we assume the version of exh defined in (3) is the relevant operator, but in Section 3 we discuss some alternatives.

$$
\operatorname{exh}_{A}(p)=p \wedge \forall q \in A(p \rightarrow q \vee \neg q)
$$

Application of exh to the predication $\mathrm{pl}(x)$ excludes $\mathrm{sg}(x)$, i.e., takes us from a weak plural interpretation to a strong one.

We show now that these assumptions make interesting predictions for plural marking, specifically its interaction with negation and other antitone environments. ${ }^{2}$ Namely, plurality is predicted to exhibit a positive polarity restriction in optional number languages. For obligatory number languages, a slight modification of our assumptions predicts that plural marking can occur in antitone environments, but that a modal effect arises (Spector 2007).

We discuss separately cases where number marking is optional and where it is obligatory. In the following discussion, we focus on cases where the optional/obligatory number marking distinction seems to be a language level parameter that applies to all nouns in all environments in a language. It is conceivable though that within a single language different nouns or different environments where nouns can occur behave differently, but we have no knowledge of such a case at this point. To keep the present discussion simple, we assume that languages like English and Latin require number marking in all instances of nouns, i.e., have obligatory number-marking, while languages like Bangla and Korean allow bare noun stems

1 Many accounts of number in English assume that noun stems are only true of atoms (Bennett 1974; Mayr 2015, and others). But Corbett (2000) reports that languages like Bayso (mentioned above) with a morphological contrast between general and singular numbers use overt morphology for singular. This morphological generalization is predicted by Assumption i. Our analysis relies on Assumption i, so would further support Assumption i if its predictions are borne out.

2 We use the order-theoretic term antitone of e.g., Birkhoff 1940 instead of downward entailing, which is ofthen used in the linguistics literature. 
to occur relatively freely, but also have number morphemes, i.e., have optional number-marking. ${ }^{3}$ The following table illustrates the analysis where exh operators are not shown:

\begin{tabular}{ccccccc} 
Form & Morphology & Interpretation & English & Latin & Bangla & Korean \\
\hline bare & $\mathrm{N}$ & $\lambda x \cdot \llbracket N \rrbracket(x)$ & $*$ & $*$ & ghora & mal \\
singular & $\mathrm{N}-[\mathrm{Sg}]_{\#}$ & $\lambda x \cdot \llbracket N \rrbracket(x) \wedge$ atom $(x)$ & horse & equ-us & ghora & mal \\
plural & $\mathrm{N}-[\mathrm{Pl}]_{\#}$ & $\lambda x \cdot \llbracket N \rrbracket(x) \wedge 1$ & horse-s & equ-i & ghora-ra & mal-tul
\end{tabular}

We discuss the predictions for optional number languages in Section 2 and those for obligatory number languages in Section 3.

\section{Predictions for optional number languages}

In this section, we show that our proposal predicts that plural marking in an optional number language should behave like a positive polarity item (PPI). Specifically, the PPI distribution is predicted from assumptions about the distribution of exh as in Spector 2014 and Nicolae 2017 and the logical structure of the alternatives. The structure of a plural noun we assume contains three propositional nodes as marked by $t: 4$

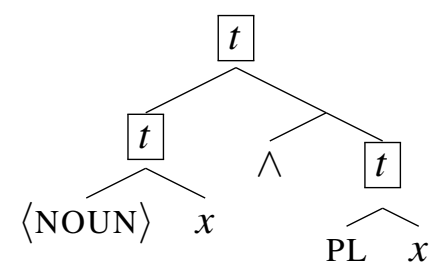

At which of the propositional nodes can or must exh apply? The most important constraint derives from assumption iii mentioned above: Meyer's Principle of Efficiency marks a structure as ungrammatical if a propositional node $N$ contains a substructure (in the sense of Katzir 2007) $N^{\prime}$ that is logically equivalent to $N$. Efficiency predicts that exh must apply to the node [PL $x$ ] in (4) because otherwise the entire structure would be equivalent to the substructure without the node [PL $x$ ]. As shown below

3 Morphologically, the distinction between the obligatory number language English and the optional number languages Bangla and Korean is not obvious. Children would need to rely on the observation of number-neutral uses of the bare nominal in Bangla and Korean to acquire that these can be bare forms.

4 See Heim \& Kratzer 1998 and Hirsch 2017 for discussion as to whether predicates of the type et can compose directly whether predicate modification. We assume here that composition via predicate modification is either optional, or not available at all (Hirsch 2017). 
in (5), exh may furthermore apply to the noun depending on whether the noun has scalar alternatives or not. Note that Meyer's principle predicts that exh should not apply vacuously, which also would generally prevent it from applying at the root node. $^{5}$

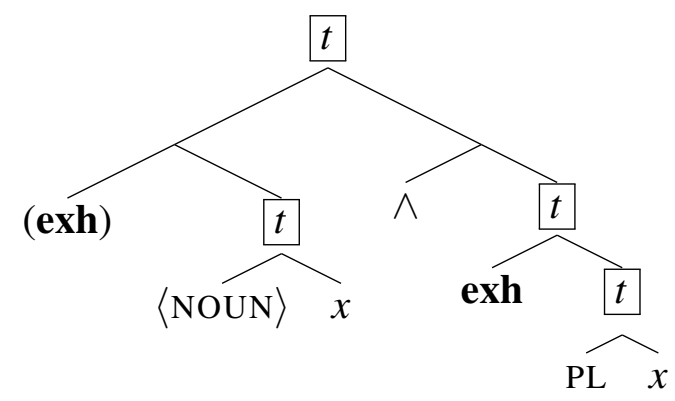

As we noted above already, application of exh results in a strong plural interpretation that excludes atoms. The derivation in (6) thus predicts that plural-marked nouns in optional number languages such as Bangla and Korean would have a 'more than one' meaning. This prediction is borne out in both languages (Kang 1994; Dayal 2014).

$$
\text { exhaustified plural: } \lambda x . \llbracket N \rrbracket(x) \wedge \operatorname{exh}_{\{\operatorname{atom}(x)\}} 1=\lambda x \cdot \llbracket N \rrbracket(x) \wedge \neg \operatorname{atom}(x)
$$

For the bare and the singular form, none of the scalar alternatives with different number marking is excludable and therefore exhaustification would not affect the interpretation. Therefore exh is blocked by Efficiency. This predicts that the bare form should be number neutral, while the singular form should always require an atom.

Now consider antitone environments. Spector (2014) and Nicolae (2017) have shown in the case of disjunction that, when exhaustification is obligatory, it can predict ungrammaticality in antitone environments. These accounts thereby explain that disjunction has the distribution of a PPI. We argue that the same reasoning is expected to apply for the plural in optional number languages. Consider the following abstract structure in (7) where a nominal predication is negated. The structure may be paraphrased only somewhat clumsily as It is not that case that $\langle$ NOUN $\rangle]+$ PL exist, but allows us to conveniently make a more general point.

5 Note that exh applying to the root node would not exclude the alternative structure with SG if the noun interpretation is distributive because then the SG alternative is entailed by the strong plural interpretation. 
(7)

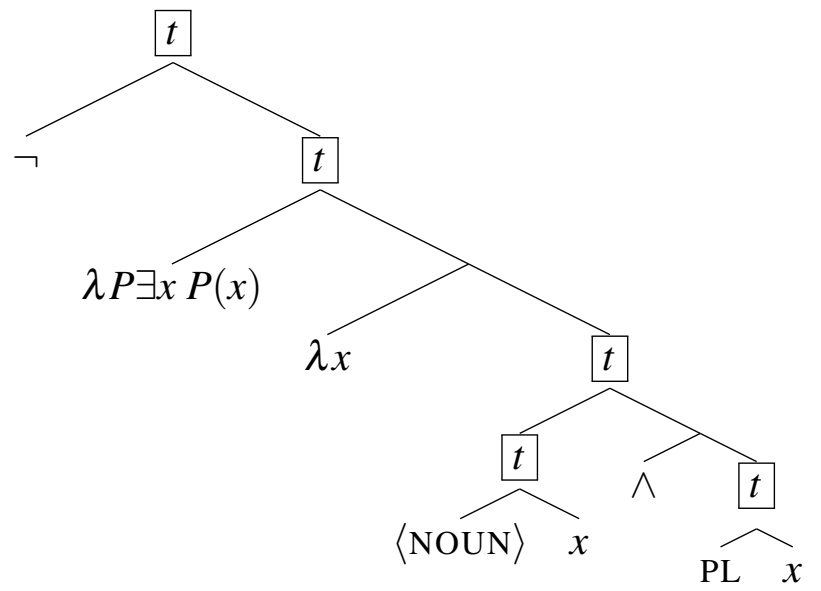

As in the unnegated structure in (5), we must examine at which of the propositional nodes exh can or must apply. The same reasoning as above establishes that exh must apply to the constituent [PL $x$ ]. But we furthermore need to verify assumption iv, the ban on global weakening. We assume that any structure $c$ with an occurrence of exh is ungrammatical if $c$ is entailed by $c^{\prime}$, where $c^{\prime}$ is derived from $c$ by deleting the occurrence of exh under consideration. The ban on global weakening was satisfied in (5), but is not generally in the negated case because the application of exh in antitone environments can lead to global weakening. The conflict between Efficiency and the ban on global weakening therefore blocks the negated structure in (7).

The reasoning illustrated in the preceding paragraph applies more generally to optional occurrences of PL in antitone environments. Therefore the analysis predicts that plural marking in optional number languages should share the distributional profile of positive polarity items such as markers of disjunction in many languages and some and rather in English. One property of the PPI distribution discussed in Spector 2014 is that presuppositional operators can allow a PPI disjunction to occur in an antitone environment. To verify that the underlying mechanism is expected to carry over to optional plurals, consider the abstract structure (8) with $\imath$ introducing an existential presupposition.

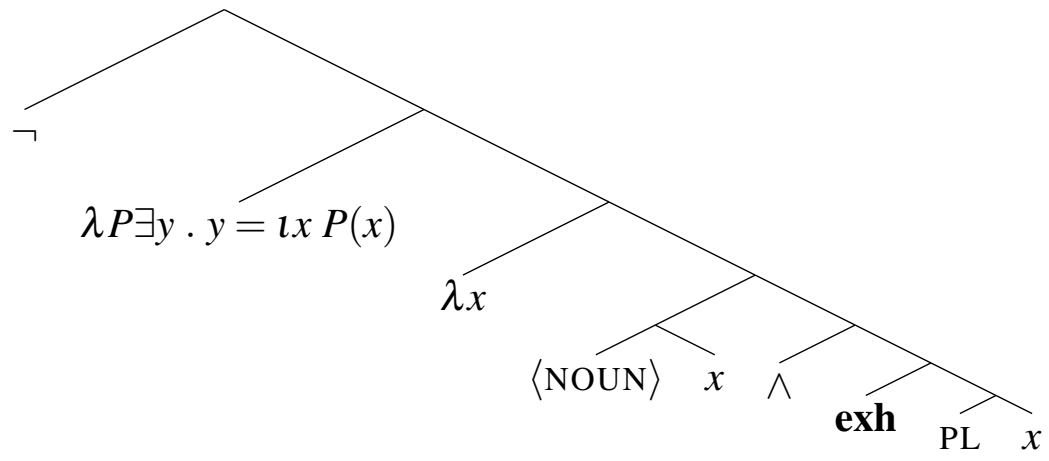


Ahn, Saha, and Sauerland

The presence of exh in (8) strengthens the presupposition in the scope of negation $\neg$ from an numberless existence presupposition to a requirement of plural existence. Since the presupposition projects through negation, the occurrence of exh in (8) satisfies the ban on global weakening. As a result the conflict between Efficiency and global weakening does not arise in (8).

While a detailed empirical verification of the prediction for optional number languages is beyond the scope of this paper, we can briefly mention some initial empirical support for the prediction from two optional number languages, Bangla and Korean. Bangla and Korean plural indefinites are predicted to behave like positive polarity items. But both Bangla and Korean are languages that do not mark definiteness overtly as English does with the (Lee 1992), though silent definiteness markers may exist in both languages (Ahn 2019 and others). As the discussion of (8) showed, the presence of even a silent definite determiner would allow a PPI plural to occur in an antitone environment. To test for PPI status, we therefore constructed contexts in which an indefinite interpretation of a noun is pragmatically likely, and we find that the plural marker - $r a$ in Bangla and -tul in Korean indeed cannot occur in antitone contexts. The data for Bangla are shown in (9), with data for Korean shown in (10).

Bangla

[Based on 5 speakers]

a. amar department-e oddhapok-(*ra) nei.

my department-LOC professor-PL be.NEG

'My department does not have professors.'

b. sob school jekhane ghora-(*ra) ache, chatro-ra horse-riding

all school where horse-PL be.PRS student-PL horse-riding sekhe.

learn.PRS.HAB

'In every school that has horses, students learn horse-riding.'

(10) Korean

[Based on 9 speakers]

a. wuli kwa-ey-nun kyoswu-ka/(*tul-i) epsta.

our department-DAT-TOP professor-NOM/PL-NOM not.exist-DECL

'Our department does not have professors.'

b. mal-i/(*tul-i) iss-nun motun hakkyo-nun sungma-lul

horse-NOM/PL-NOM exist-RC every school-TOP horseriding-ACC

kaluchin-ta.

teach-DECL

'Every school that raises horses teach horseriding.'

There are several external factors that affect the overall degradedness of the plural markers in both of these languages. These include the existence presupposition 
rescuing the plural-marked noun, though the effect does not seem to attest itself in (9b) or (10b). Furthermore, competition with other plural markers such as gulo in Bangla, as well as interaction with other factors such as politeness must be considered. Despite these confounds, the discussion of which fall beyond the scope of this paper, the generalization we can draw is that plural indefinites in Bangla and Korean are degraded in some antitone contexts.

\section{Predictions for obligatory number}

In this section, we consider plural marking in antitone environments in obligatory number languages. We first demonstrate that plural marking is not predicted to exhibit a PPI distribution in obligatory number languages. Then we discuss a subtle difference between singular and plural indefinites in antitone environments observed in Spector 2007. While Spector leaves these data as a puzzle, we show that our account allows an analysis of this puzzle. However, the analysis requires us to adopt the view that exhaustification is not based on the exh operator we assumed in the preceeding discussion, but the presuppositional variant pex in Bassi, Del Pinal \& Sauerland 2019. Finally we show that the PPI distribution of the plural markers in optional number languages that we discussed in Section 2 still arises as a prediction even when we assume pex instead of exh.

If number marking on nouns is obligatory, the only two possible structures are $\langle$ NOUN $\rangle+$ SG and $\langle$ NOUN $\rangle+$ PL. Because the bare noun is not a possible structure, Efficiency does not require exh to always apply locally to the plural marker in obligatory number languages. Without any further assumptions, this proposal predicts that plurals should allow a weak meaning in obligatory number languages such that it is compatible with a singular reference. Note, however, that examples like (11) is odd in contrast to this prediction.

(11) \#Jill has brothers. Namely she has one brother.

We show that (11) is not problematic for our prediction because this oddness is also found for other scalar items such as some and partitive of in (12), and has been addressed by several authors. ${ }^{6}$ For example, Meyer (2014: 584) suggests deriving the oddness of under-informative assertions such as in (11) and (12) from her principle Epistemic Transparency. Specifically Meyer argues that assertions contain a silent modal $\mathrm{K}$ expressing speaker certainty. Epistemic Transparency requires that any occurrence of $\mathrm{K} \phi$ entails the speaker's epistemic attitude about every element $\psi \in \operatorname{Alt}(\phi)$, i.e. entail either $\mathrm{K} \psi$ or $\neg \mathrm{K} \psi$. Meyer notes that if $\phi$ has

6 The experimental literature on scalar implicatures reveals a more gradient picture and effects of age (Chemla \& Singh 2014, and others). As far as we know, the state of affairs is similar for plurals (Tieu, Bill, Romoli \& Crain 2020; Yatsushiro, Sauerland \& Alexiadou 2017, and others). 
Ahn, Saha, and Sauerland

any logically non-weaker alternatives, $\mathrm{K} \phi$ will not satisfy Epistemic Transparency while exh $\mathrm{K} \phi$ always does and other representations with at least one exh in the scope of $K$ such as $\mathrm{K} \operatorname{exh} \phi$ or $\operatorname{exh} \mathrm{K} \operatorname{exh} \phi$ may too.

(12) \# Mary drank some of the beers. Namely she drank all of them.

Meyer's Epistemic Transparency predicts for the alternative $\psi$ 'Mary drank all of the beers' the following: (12) must entail $\neg \mathrm{K} \psi$ since there is no possible representation for (12) that entails $\mathrm{K} \psi$. To apply the same reasoning to (11), we put aside details of possessive have and consider it as structure where PL is interpreted in the scope of an existential quantifier. Consider first (13) with a single occurrence of exh. While (13) could satisfy Epistemic Transparency, it contradicts the distributivity of the predicate 'brother' because it entails that the speaker simultaneously is certain that Mary has brothers, but uncertain as to whether Mary has a single brother.

$$
\# \operatorname{exh} \mathrm{K} \exists x[\operatorname{brother}(\mathrm{Jill})(x) \wedge \operatorname{PL}(x)]
$$

Spector (2007) shows that plurality requires multiple exhaustification to generate implicatures that are consistent with homogeneity. ${ }^{7}$ Within our set of assumptions, consider the two representations in (14). ${ }^{8}$

$$
\begin{aligned}
& \text { a. } \quad \operatorname{exhK\operatorname {exh}} \exists x[\operatorname{brother}(\operatorname{Jill})(x) \wedge \operatorname{exh} \operatorname{PL}(x)] \\
& \text { b. K exh exh } \exists x[\operatorname{brother}(\operatorname{Jill})(x) \wedge \operatorname{exh} \operatorname{PL}(x)]
\end{aligned}
$$

In the evaluation of the first exh of both representations in (14), the alternative (15) with SG instead of PL plays a role (for (14a), (15) would be preceded by K). Because (15) in turn excludes the exhaustified PL, it can be paraphrased as Jill has exactly one brother. The exclusion of (15) or K (15) therefore predicts (11) to be odd.

$$
\begin{aligned}
& \operatorname{exh} \exists x[\operatorname{brother}(\operatorname{Jill})(x) \wedge \operatorname{exh~SG}(x)] \\
\Leftrightarrow & \exists x[\operatorname{brother}(\operatorname{Jill})(x) \wedge \mathrm{SG}(x)] \wedge \neg \exists x[\operatorname{brother}(\operatorname{Jill})(x) \wedge \mathrm{PL}(x) \wedge \neg \mathrm{SG}(x)]
\end{aligned}
$$

Now consider the effect of negation in obligatory number languages. Our approach predicts that plurals should not be PPIs. This follows directly from the

7 We have not considered innocent inclusion as an alternative to multiple exhaustification for our data at this point (Bar-Lev \& Fox 2017; Bar-Lev 2018).

8 Note that in an obligatory number language the innermost occurence of exh could take over the NP, but the variants in (ia) and (ib) will be equivalent to their respective counterparts when the noun does not have scalar alternatives.

$$
\begin{aligned}
& \text { a. } \quad \operatorname{exh} \mathrm{K} \operatorname{exh} \exists x \operatorname{exh}[\operatorname{brother}(\operatorname{Jill})(x) \wedge \operatorname{PL}(x)] \\
& \text { b. K exh exh } \exists x \operatorname{exh}[\operatorname{brother}(\operatorname{Jill})(x) \wedge \operatorname{PL}(x)]
\end{aligned}
$$


observation that (16) satisfies Meyer's Epistemic Transparency without any occurrence of exh because (16) is of the form $\mathrm{K} \phi$ where all scalar alternatives of $\phi$ are entailed by $\phi$. In this case, exhaustification is not required.

$$
\mathrm{K} \neg \exists x[\operatorname{brother}(\operatorname{Jill})(x) \wedge \operatorname{PL}(x)]
$$

This correctly predicts that for languages like English, a plural can be negated and have a weak reading as in (17) (Hoeksema 1983; van Eijck 1983; Spector 2007, and others).

Jill doesn't have brothers.

Note that the difference in prediction between optional and obligatory number languages arises even though both require exh to apply locally to PL inside the noun phrase. The different interaction with antitone environments derives from the different conditions of Meyer's theory that require the presence of a local exh in the two kinds of languages. In optional number languages, it is Efficiency that requires exh and therefore exh is also required in antitone environments. But in obligatory plural languages, only Epistemic Transparency makes exh necessary and the requirement therefore does not apply to occurrences of PL in an antitone environment.

One puzzle remains though. This puzzle is due to Spector (2007) and has not been satisfactorily solved to our knowledge. Spector observes that (18a) and (18b) are predicted to be equivalent if plurals include singular reference. But surprisingly (18b) is perceived to be odd while (18a) is acceptable.

$$
\begin{aligned}
& \text { a. Jack doesn't have a father. } \\
& \text { b. \#Jack doesn't have fathers. }
\end{aligned}
$$

An analysis of (18b) analogous to (16) would not capture the restriction Spector observes. We speculate that a variant of our approach that relies on the presuppositional version of the exhaustification operator of Bassi et al. (2019) would be able to capture Spector's observation. Consider the definition of pex in (19) where we use the fraction notation in Harbour 2014 for presuppositions. ${ }^{9}$

$$
\operatorname{pex}_{A}(p)=\frac{p}{\forall q \in A(p \rightarrow q \vee \neg q)}
$$

Now consider (18a). Our assumptions predict for (18a) the logical form (20)

9 In the Heim \& Kratzer 1998 notation, pex would be stated as follows:

$$
\operatorname{pex}_{A}(p)=\lambda w: \forall q \in A(p \rightarrow q \vee \neg q(w)) \cdot p(w)
$$


(again putting aside details of possessive have).

$$
\text { Knot pex } \exists x[\text { pex SG }(x) \wedge \text { father }(\text { Jack })(x)]
$$

Because the inner occurrence of pex is in the scope of an existential quantifier that accommodates the presupposition of pex, we can treat is just as exh. But the presupposition of the outer pex projects through the negation. The alternative that the outer pex excludes contains the exhaustified plural.

$$
\frac{\mathrm{K} \neg \exists x[\mathrm{SG}(x) \wedge \text { father }(\text { Jack })(x)]}{\mathrm{K} \neg \exists x[\neg \mathrm{SG}(x) \wedge \text { father }(\text { Jack })(x)]}
$$

The presupposition in the denominator of (21) states that Jack doesn't have more than a single father. ${ }^{10}$ This presupposition is satisfied for (18a), while the oddness of $(18 \mathrm{~b})$ indicates that it has the complementary presupposition.

A complementarity of the presuppositions like that of (18a) and (18b) has been observed in a number of cases, frequently referred to as Presupposition Maximization (Heim 1991; Percus 2006; Sauerland 2008; Singh 2011; Elliott \& Sauerland 2019, and others). We think any proposal that derives such complementary presuppositions generally can then account for (18a) and (18b).

To sum up the final speculation regarding Spector's puzzle, the replacement of exh with pex might be able to provide an account of the long-standing problem in (18b). But we have not integrated this account yet with the other parts of our analysis. In particular, the introduction of pex instead of exh may affect the predictions of our theory for optional number languages especially since we showed in Section 2 that presuppositionality plays a role in our account. But in the relevant examples in Section 2, exh occurs in the direct scope of an existential quantifier where accommodation of the presupposition may be forced. Therefore we are optimistic that future work will be able to implement our account of optional number languages using pex instead of exh.

\section{Conclusion}

In this paper, we explore the theoretical consequences of the assumption that number marking on nouns may be optional in some languages and obligatory in others. We show that, with independently-motivated assumptions, we are able to account for a novel observation that plurals are positive polarity items in optional number

10 The presupposition initially seems too strong for examples like Jack doesn't have a brother. Possibly it can be tacitly accommodated though since it is asymmetrically entailed by the assertion. 
languages, but not in obligatory number languages. We furthermore note that the use of pex, a presuppositional variant of exh (Bassi et al. 2019), may account for the puzzle from Spector 2007, specifically that a plural noun and an indefinite noun in English differs in acceptability in an antitone environment.

\section{References}

Ahn, Dorothy. 2019. THAT thesis: A competition mechanism for anaphoric expressions. Cambridge, Mass.: Harvard University $\mathrm{PhD}$ dissertation.

Arka, I Wayan \& Mary Dalrymple. 2017. Nominal, pronominal, and verbal number in Balinese. Linguistic Typology 21(2).

Bar-Lev, Moshe E. 2018. Free choice, Homogeneity, and Innocent Inclusion: Hebrew University of Jerusalem $\mathrm{PhD}$ dissertation.

Bar-Lev, Moshe E. \& Danny Fox. 2017. Universal free choice and innocent inclusion. In Semantics and Linguistic Theory (SALT), vol. 27, 95-115. doi:10.3765/salt.v27i0.4133.

Bassi, Itai, Guillermo Del Pinal \& Uli Sauerland. 2019. Presuppositional exhaustification. Unpublished ms.

Bennett, Michael. 1974. Some extensions of a Montague fragment of English: UCLA $\mathrm{PhD}$ dissertation.

Birkhoff, Garrett. 1940. Lattice theory. American Mathematical Society.

Biswas, Priyanka. 2013. Plurality in a classifier language: Two types of plurals in Bangla. Proceedings of Generative Linguists of the Old World in Asia (GLOW in Asia) 1-14.

Bylinina, Lisa \& Alexander Podobryaev. 2020. Plurality in Buriat and structurally constrained alternatives. Journal of Semantics 37. 117-128. doi:10.1093/jos/ffz017.

Chemla, Emmanuel \& Raj Singh. 2014. Remarks on the experimental turn in the study of scalar implicature, parts I \& II. Language and Linguistics Compass 8(9). 373-399.

Chierchia, Gennaro. 2013. Logic in grammar: Polarity, free choice, and intervention. Oxford, UK: Oxford University Press.

Chierchia, Gennaro, Danny Fox \& Benjamin Spector. 2012. Scalar implicature as a grammatical phenomenon. In Klaus von Heusinger, Claudia Maienborn \& Paul Portner (eds.), Handbook of Semantics, vol. 3, 2297-2331. Mouton de Gruyter. doi:10.1515/9783110253382.2297.

Corbett, Greville. 2000. Number. Cambridge, UK: Cambridge University Press.

Corbett, Greville G. \& Richard J Hayward. 1987. Gender and number in Bayso. Lingua 73(1-2). 1-28. 
Dayal, Veneeta. 2014. Bangla plural classifiers. Language and Linguistics 15(1). 47-87.

van Eijck, Jan. 1983. Discourse representation theory and plurality. In Alice ter Meulen (ed.), Studies in Modeltheoretic Semantics, 85-106. Dordrecht: Foris.

Elliott, Patrick D. \& Uli Sauerland. 2019. Ineffability and unexhaustification. In M. Teresa Espinal et al. (eds.), Sinn und Bedeutung 23 (SuB), vol. 1, 399-411. Bellaterra: Universitat Autònoma de Barcelona.

Fox, Danny \& Benjamin Spector. 2018. Economy and embedded exhaustification. Natural Language Semantics 26. 1-50.

Harbour, Daniel. 2014. Paucity, abundance, and the theory of number. Language 90. 185-229. doi:10.1353/lan.2014.0003.

Heim, Irene. 1991. Artikel und Definitheit, 487-535. Berlin, Germany: de Gruyter.

Heim, Irene \& Angelika Kratzer. 1998. Semantics in generative grammar. Oxford, UK: Blackwell.

Hirsch, Aron. 2017. An inflexible semantics for cross-categorial operators. Cambridge, Mass.: Massachusetts Institute of Technology PhD dissertation.

Hoeksema, Jack. 1983. Plurality and conjunction. In Alice ter Meulen (ed.), Studies in Modeltheoretic Semantics, 63-83. Dordrecht: Foris.

Kang, Beom-Mo. 1994. Plurality and other semantic aspects of common nouns in Korean. Journal of East Asian Linguistics 3(1). 1-24.

Katzir, Roni. 2007. Structurally-defined alternatives. Linguistics and Philosophy 30. 669-690. doi:10.1007/s10988-008-9029-y.

Kim, Chonghyuk. 2005. The Korean plural marker tul and its implications: University of Delaware $\mathrm{PhD}$ dissertation.

Lee, Chungmin. 1992. Definite/specific and case marking in Korean. Theoretical issues in Korean linguistics 325-341.

Mayr, Clemens. 2015. Plural definite NPs presuppose multiplicity via embedded exhaustification. In Semantics and Linguistic Theory (SALT), vol. 25, 204-224.

Meyer, Marie-Christine. 2013. Ignorance and grammar. Cambridge, Mass.: Massachusetts Institute of Technology PhD dissertation.

Meyer, Marie-Christine. 2014. Deriving Hurford's constraint. In Semantics and Linguistic Theory (SALT), vol. 24, 577-596.

Meyer, Marie-Christine. 2015. Redundancy and embedded exhaustification. In S. D'Antonio, M. Moroney \& C.R. Little (eds.), Semantics and Linguistic Theory (SALT), vol. 25, 491-511.

Nicolae, Andreea C. 2017. Deriving the positive polarity behavior of plain disjunction. Semantics \& Pragmatics 10.

Percus, Orin. 2006. Antipresuppositions. In Ayumi Ueyama (ed.), Theoretical and Empirical Studies of Reference and Anaphora: Toward the Establishment of Generative Grammar as an Empirical Science, 52-73. Fukuoka, Japan: Kyushu 
University.

Sauerland, Uli. 2003. A new semantics for number. In Robert B. Young \& Yuping Zhou (eds.), Semantics and Linguistic Theory (SALT), vol. 13, 258-275. Cornell University Ithaca, N.Y.: CLC-Publications.

Sauerland, Uli. 2008. Implicated presuppositions. In Anita Steube (ed.), The Discourse Potential of Underspecified Structures, 581-600. Berlin, Germany: Mouton de Gruyter.

Sauerland, Uli. 2018. The Thought Uniqueness Hypothesis. In Semantics and Linguistic Theory (SALT), vol. 28, 289-306.

Sauerland, Uli, Jan Anderssen \& Kazuko Yatsushiro. 2005. The plural is semantically unmarked. Linguistic Evidence: Empirical, Theoretical, and Computational Perspectives 413-434.

Singh, Raj. 2011. Maximize presupposition! and local contexts. Natural Language Semantics 19. 149-168. doi:10.1007/s11050-010-9066-2.

Spector, Benjamin. 2007. Aspects of the pragmatics of plural morphology: On higher-order implicatures, 243-281. Basingstoke, UK: Palgrave Macmillan.

Spector, Benjamin. 2014. Global positive polarity items and obligatory exhaustivity. Semantics and Pragmatics 7(11). 1-61. doi:10.3765/sp.7.11.

Tieu, Lyn, Cory Bill, Jacopo Romoli \& Stephen Crain. 2020. Testing theories of plural meanings. Cognition (in press). doi:10.1016/j.cognition.2020.104307.

Yatsushiro, Kazuko, Uli Sauerland \& Artemis Alexiadou. 2017. The unmarkedness of plural: Crosslinguistic data. In Maria LaMendola \& Jennifer Scott (eds.), Boston University Conference on Language Development (BUCLD 41), 753765.

Dorothy Ahn

Department of Linguistics

Rutgers University

18 Seminary Place

New Brunswick, NJ

USA

dorothy.ahn@rutgers.edu

Uli Sauerland

ZAS

Schuetzenstrasse 18

10117 Berlin

Germany

uli@alum.mit.edu
Ankana Saha

Department of Linguistics

Harvard University

Boylston Hall, 3rd Floor

Cambridge, MA

USA

ankana_saha@g.harvard.edu 